\title{
Microwave effect on ion-exchange and structure of clinoptilolite
}

\author{
Y. Akdeniz $\cdot$ S. Ülkü
}

Received: 25 May 2005 / Revised: 30 March 2006/Published online: 6 February 2007

(C) Springer Science+Business Media, LLC 2007

\begin{abstract}
The effect of microwave irradiation on the ion exchange degree and structure of clinoptilolite mineral has been examined in comparison with the conventional heat treatment in waterbath. Clinoptilolite-rich mineral from the Western Anatolia, Bigadiç region was used for the experimental study. The mineral was mainly clinoptilolite (80-85\%) and additionally, quartz (5-10\%), and analcime + mordenite $(<5 \%)$ were found as co-existing minerals. The mineral was stable towards dehydration and maintains its original structure up to $800^{\circ} \mathrm{C}$. The BET and Langmuir surface areas of the sample were found to be 22 and $17 \mathrm{~m}^{2} / \mathrm{g}$ for $\mathrm{N}_{2}$ adsorption and 28 and $22 \mathrm{~m}^{2} / \mathrm{g}$ for Ar adsorption, respectively. For the exchange experiments, clinoptilolite rich mineral was treated with $1 \mathrm{~N}$ $\mathrm{NaCl}$ salt solution both in a microwave unit and waterbath for $10 \mathrm{~min}, 1 \mathrm{~h}$ and $2 \mathrm{~h}$ at $80{ }^{\circ} \mathrm{C}$. The waterbath treatment with the same conditions was continued for two additional weeks. The chemical composition of the parent and Na-exchanged forms of the clinoptilolite rich minerals were analyzed by using Inductively Coupled Plasma Atomic Emission Spectroscopy (ICP-AES). Microwave treatment was found to be more rapid and effective for ion exchange compared to conventional waterbath treatment. Additionally, the XRD results reveal that microwave irradiation has zero effect on the structure of the clinoptilolite rich mineral.
\end{abstract}

Y. Akdeniz $(\bowtie) \cdot$ S. Ülkü

Faculty of Engineering, Chemical Engineering Department, Izmir Institute of Technology Gülbahçe Köyü, Urla, İzmir, Turkey

e-mail: yeldaakdeniz@iyte.edu.tr
Keywords Clinoptilolite $\cdot$ Microwave treatment . Ion exchange $\cdot \mathrm{X}$-ray diffraction

\section{Introduction}

Zeolites are crystalline aluminosilicates of group IA and IIA elements such as sodium, potassium, barium, magnesium and calcium. They are formed by the reaction of pore-waters with volcanic glass and also by the alteration of pre-existing feldspar, feldspathodoids, poorly crystalline clays and biogenic silica. The fundamental building unit of the zeolite is a tetrahedron of four oxygen atoms surrounding a relatively small silicon or aluminum atom. The structure is porous with interconnected cavities in which metal cations and water molecules exist [1].

Zeolites are considered to be unique due to their special properties which are influenced by their framework and extra-framework composition. The number, type and location of the exchangeable cations strongly affect the ion exchange performance of zeolites [2]. The ion-exchange, adsorption, and molecular sieve properties of zeolites lead them to be used for different applications such as wastewater treatment, stack-gas clean-up, natural gas purification, agricultural, aquacultural, petroleum production and etc [3]. Recently, zeolites have been found out to be useful for applications in pharmacy, biology and drug systems. Cation exchanged forms of zeolites are used as antibacterial material against some microorganisms. Their antiviral properties of clinoptilolite that cause the possible use of zeolites in therapeutical applications; either locally (skin) against herpesvirus infections or orally in cases of adenovirus or enterovirus infections. 
Although synthetic zeolites are now being used for the above applications, utilization of natural zeolites as cation exchangers has received increasing interest due to their availability and low cost $[4,5]$.

Clinoptilolite, the most widespread natural zeolite with high silica amount, is a member of heulandite group of natural zeolites. Its structure consists of a two dimensional system of the three types of channels. Two parallel channels, channel A (10 member ring) and channel B (8 member ring) which are perpendicularly intersected by channel $\mathrm{C}$ ( 8 member ring) with sizes $4.4 \times 7.2 \AA, 4.1 \times 4.7 \AA$ and $4.0 \times 5.4 \AA$, respectively [6]. The main cations located in cationic sites are $\mathrm{Na}$, $\mathrm{Ca}, \mathrm{K}, \mathrm{Mg}$ and $\mathrm{Ba}$ [7].

Microwaves are a kind of electromagnetic radiation with a high frequency between 0.3 and $300 \mathrm{GHz}$. They are in the form of radiowaves that pass through the material. The energy transformation into the material occurs through different mechanisms; which are ionic conduction and dipole interaction [8]. In ionic conduction, charged particles oscillate back and forth under the influence of microwaves and collide with each other. This collision causes molecular orientation or friction and creates heat. In the dipole interaction, molecules with a permanent dipole are submitted to an electric field they become aligned. If this field oscillates, the orientation of the molecules changes with each alternation and the reorientation of molecules cause an intense internal heating. In the microwave heating system, microwaves penetrate to the core of a substance and directly heat the inside preventing the formation of temperature gradient. In the conventional heating systems, heat is transmitted from the exterior surface of the substance into its interior through of thermal conduction [9].

The use of microwaves became increasingly popular in many fields of science such as, biology, medicine, chemistry and chemical engineering. Recently, a new interdisciplinary field of microwave chemistry has emerged. It has many advantages-for instance it supplies uniform and direct heating, lower temperature for some processes, enhances the reaction speed, reduces time and cost of the processes used [2-5, 9-15].

Katsuki et al. [12] claimed that the kinetics of $\mathrm{NaY}$ zeolite crystals with microwaves were enhanced by 3 to 4 times compared to conventional hydrothermal method. Pilter et al. [14] studied the effect of microwave irradiation on zeolite $\mathrm{Na}-\mathrm{A}$ in comparison with conventional heat treatment. They found that zeolite structure was gradually changed during conventional heat treatment whereas in microwave treatment, the zeolite structure directly converted into other crystalline phase. Stout and Komarneni [16] studied the ability of removal of $\mathrm{K}^{+}$from the solution containing sodium tetraphenylborate (NaTPB) from the interlayers of naturally occurring phlogopite using microwave and conventional heating treatments. They concluded that microwave assisted treatment considerably decreased the exchange time. As described in other studies, the use of microwaves decreased the temperature required for complete desorption of water, and modifications by ion exchange showed no structural changes [11]. Energy absorption in zeolites is a complex process and it is thought to be strongly affected by the presence of metal ions. $\mathrm{Na}^{+}$ions within the large cavity of zeolites act as strong microwave absorbers [5, 6, 14-19]. Molecular sieve membranes consisting of Na-A zeolite crystals on $\alpha-\mathrm{Al}_{2} \mathrm{O}_{3}$ substrate have been successfully synthesized by means of microwaves. This type of synthesis greatly decreased the reaction time and membranes were found very stable and dense [20].

Although scientists have done many researches by using microwave, the mechanism of interaction of microwave radiation with a material has not been thoroughly understood; however, microwave treated material may show structural changes during treatment. The aim of this study is (a) to investigate the efficiency of the $\mathrm{Na}^{+}$exchange process under microwave irradiation in comparison with the conventional waterbath treatment and (b) to study the effect of microwave irradiation on clinoptilolite structure.

\section{Materials and methods}

The clinoptilolite rich mineral used in this study was obtained from Bigadiç region, Western Anatolia, Turkey. The mineral was ground and sieved. For characterization experiments, $45-75 \mu \mathrm{m}$ portion was used and it was kept in fully hydrated in a desiccator saturated with $\mathrm{NH}_{4} \mathrm{Cl}$ solution.

Thermal analyses were done using Thermogravimetric Analyzer (TGA-51/51H, Schimadzu), Differential Scanning Calorimetry (DSC-50, Schimadzu) and Differential Thermal Analysis (DTA-50, Schimadzu) with a heating rate of $10{ }^{\circ} \mathrm{C} / \mathrm{min}$ under $40 \mathrm{ml} / \mathrm{min} \mathrm{N}_{2}$ atmosphere. The TGA, DTA and DSC curves of the parent mineral are given in Fig. 1. The clinoptilolite mineral has $13.5 \%$ water content, structural changes were started around $600{ }^{\circ} \mathrm{C}$ and structure was collapsed at $830{ }^{\circ} \mathrm{C}$.

The X-ray powder diffraction (XRD) measurements were carried out using a Philips X/Pert X-ray diffractometer with $\mathrm{Ni}$ filtered $\mathrm{CuK}_{\alpha}$ radiation in the range of 

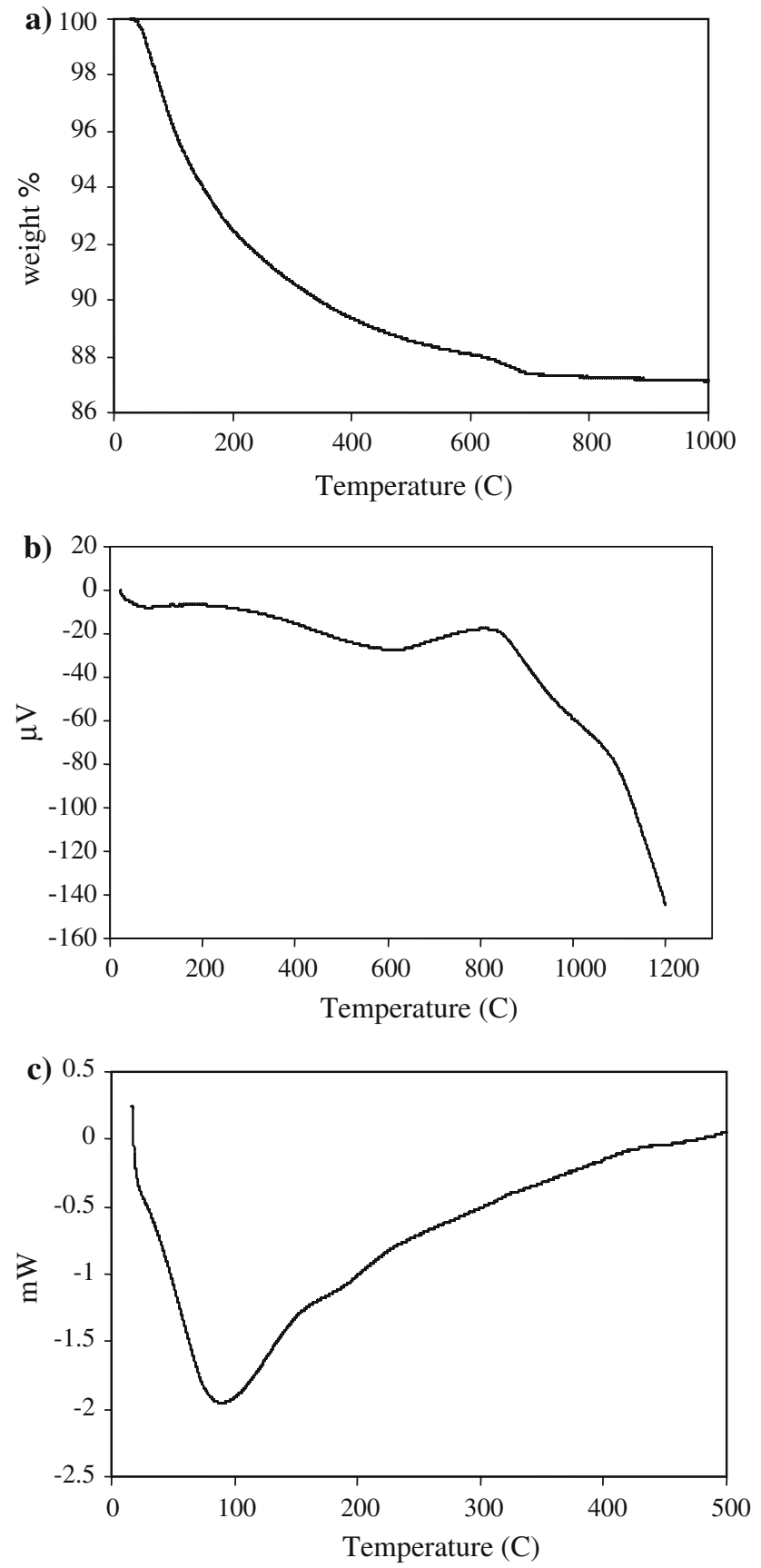

Fig. 1 Thermal behavior of clinoptilolite mineral, Bigadiç (a) TGA (b) DTA and (c) DSC

$2 \theta$ values $5-40^{\circ}$ and given in Fig. 2. The characteristics peaks of Clinoptilolite were found on the XRD pattern. Parent mineral was mainly clinoptilolite $(80$ $85 \%$ ), additionally it contains $5-10 \%$ quartz, $<5 \%$ analcime and/or mordenite (Fahri Esenli, Personal Communications).

The adsorption related properties of clinoptilolite rich mineral was determined by means of volumetric

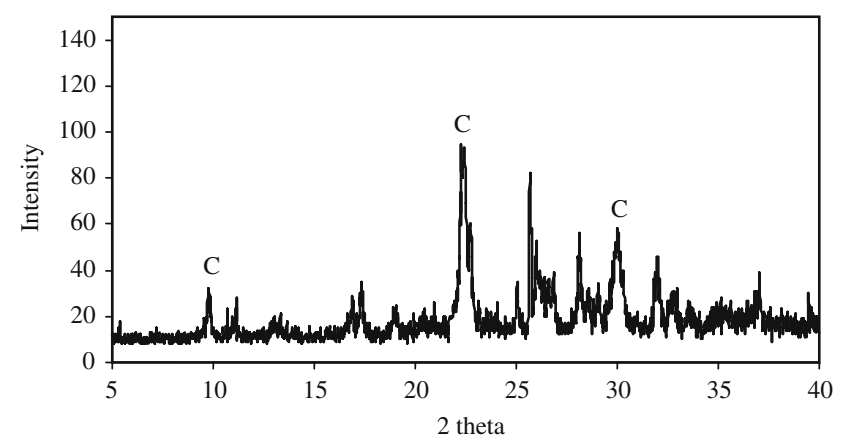

Fig. 2 XRD pattern of clinoptilolite mineral, Bigadiç

system (Micromeritics-ASAP 2010). The samples were dried in vacuum oven at $160^{\circ} \mathrm{C}$ for at least $4 \mathrm{~h}$. The dried samples were then degassed at $350{ }^{\circ} \mathrm{C}$ under $10^{-5} \mathrm{mmHg}$ for $24 \mathrm{~h}$ prior to adsorption measurements. The analyses were carried out in liquid $\mathrm{N}_{2}$ bath with nitrogen and argon gases. BET and Langmuir Surface Areas were calculated and are given in Table 1.

The chemical analysis of the mineral was determined by Inductively Coupled Plasma Atomic Emission Spectroscopy (ICP-AES) and the results are tabulated in Table 2. The analyses were done using the method of acid digestion where small amount of clinoptilolite ( $\cong 0.1$ gr.) was dissolved in appropriate amounts of $\mathrm{HF}, \mathrm{HNO}_{3}$ and $\mathrm{HCl}$ acids. The weight percentages of trace elements were found as; $\mathrm{Cu}^{2+}$ $\left(3 \times 10^{-3}\right), \quad \mathrm{Li}^{+}\left(17 \times 10^{-3}\right), \mathrm{Mn}^{2+}\left(12 \times 10^{-3}\right), \quad \mathrm{Co}^{3+}$ $\left(3 \times 10^{-3}\right), \quad \mathrm{Cr}^{3+}\left(1 \times 10^{-3}\right), \quad \mathrm{Ni}^{2+} \quad\left(7 \times 10^{-3}\right), \quad \mathrm{Pb}^{2+}$ $\left(10 \times 10^{-3}\right)$ and $\mathrm{Zn}^{2+}\left(7 \times 10^{-3}\right)$.

Table 1 Properties of clinoptilolite mineral, Bigadiç

\begin{tabular}{lll}
\hline $\begin{array}{l}\text { Water content-TGA } \\
\text { Dehydration } \\
\text { behavior-DSC }\end{array}$ & $\begin{array}{c}13.5 \% \\
\text { Endotherm }\end{array}$ & \\
$\begin{array}{l}\text { Dehydration } \\
\text { behavior-DTA }\end{array}$ & $\begin{array}{c}\text { Endotherm } \\
\text { @ } 62.4^{\circ} \mathrm{C}\end{array}$ & $\begin{array}{c}\text { Exotherm } \\
\text { @ } 833^{\circ} \mathrm{C}\end{array}$ \\
$\begin{array}{l}\text { BET Surface Area for } \\
\left(\mathrm{m}^{2} / \mathrm{g}\right)\end{array}$ & $\begin{array}{l}\mathrm{N}_{2} \text { Adsorption } \\
\text { Langmuir Surface Area } \\
\left(\mathrm{m}^{2} / \mathrm{g}\right)\end{array}$ & $\begin{array}{c}\text { Ar Adsorption } \\
17.25\end{array}$ \\
\hline
\end{tabular}

Table 2 Chemical composition clinoptilolite mineral, Bigadiç

\begin{tabular}{lc}
\hline Major elements & \% Weight \\
\hline $\mathrm{Al}_{2} \mathrm{O}_{3}$ & 10.20 \\
$\mathrm{Si}_{2} \mathrm{O}$ & 67.48 \\
$\mathrm{BaO}$ & 0.24 \\
$\mathrm{CaO}$ & 2.29 \\
$\mathrm{Fe}_{2} \mathrm{O}_{3}$ & 1.02 \\
$\mathrm{~K}_{2} \mathrm{O}$ & 2.23 \\
$\mathrm{MgO}$ & 1.35 \\
$\mathrm{Na}_{2}$ & 0.52 \\
\hline
\end{tabular}


For ion exchange experiments, $2-4.45 \mathrm{~mm}$ portion of the clinoptiloite rich mineral was used. The experiments were performed using both conventional waterbath and microwave treatment methods. In conventional treatment, $100 \mathrm{gr}$ of samples were put into in $1,600 \mathrm{ml} 1 \mathrm{~N}$ $\mathrm{NaCl}$ solution which was maintained at $80^{\circ} \mathrm{C}$ for $10 \mathrm{~min}, 1 \mathrm{~h}, 2 \mathrm{~h}$ and 2 week. In microwave treatment, $0.5 \mathrm{~g}$ samples were put into $10 \mathrm{ml}$ of $1 \mathrm{~N} \mathrm{NaCl}$ solution and placed in a specially made Teflon-lined polyamide vessels (Mars 5, Model XP-1500, CEM Corp.) The frequency and maximum power of the microwave was $2.450 \mathrm{GHz}$ and $1.2 \mathrm{KW}$, respectively. The safety temperature and pressure of the microwave was set to $80{ }^{\circ} \mathrm{C}$ and 120 psia, respectively, and microwave power was adjusted to $300 \mathrm{~W}$. Two replicates for each run were done for the both treatments. After the exchange, the samples were washed with double-distilled water until all $\mathrm{Cl}^{-}$was removed, and dried in an oven at $160{ }^{\circ} \mathrm{C}$ for $4 \mathrm{~h}$ and kept in dry desiccator for ICP analyses.

\section{Results and discussion}

In this study, effectiveness, validity and advantages of microwave and commercial waterbath treatment methods on exchange mechanism of clinoptilolite rich mineral were tested considering both the engineering and economical aspects. Weight percentages of the cations $\mathrm{Ca}^{2+}, \mathrm{Fe}^{3+}, \mathrm{K}^{+}, \mathrm{Mg}^{2+}$ and $\mathrm{Na}^{+}$in the mineral phase are given in Table 3 which summarizes the exchange kinetics of clinoptilolite rich mineral.

It is clear that, the behavior of each cation varies for the exchange process. Since $\mathrm{Cu}^{2+}, \mathrm{Li}^{+}, \mathrm{Mn}^{2+}, \mathrm{Co}^{3+}$, $\mathrm{Cr}^{3+}, \mathrm{Ni}^{2+}, \mathrm{Pb}^{2+}$ and $\mathrm{Zn}^{2+}$ amounts in the zeolite were very small and caused quite small changes in the clinoptilolite structure; they are not taken into consideration in this study. In the clinoptilolite rich mineral, noticeable changes were detected for the $\mathrm{Mg}^{2+}$ and $\mathrm{K}^{+}$ cations; however, the major change was observed in the case of $\mathrm{Ca}^{2+}$ that was exchanged with $\mathrm{Na}^{+}$. The higher $\mathrm{Na}^{+}$exchange degree compared to other cations could be explained by the structural location of $\mathrm{Na}^{+}$ and $\mathrm{Ca}^{2+}$ within the mineral. Additionally, the difference in the hydrated radii of the cations associated with each other leads higher exchange degree of $\mathrm{Na}^{+}$[21]. The cation balance error values (CBE \%) are quite low for all experimental runs which indicate the reliability of the zeolite compositions and experiments.

The weight $\%$ of the major exchanged cations in the mineral phase versus time using microwave and waterbath treatment are given in Fig. 3.

The size of the hydrated ionic radii of the cations strongly affects the exchange degree since there is a direct relation with each other. The ionic radius, hydrated radius and hydration energies of various cations are summarized in Table 4. When the hydrated radii of the ions are approximately the same size as the channel dimensions, the exchange becomes difficult. The divalent cations usually have higher radius than monovalent cations [12]. Cations such as $\mathrm{Ca}^{2+}, \mathrm{Mg}^{2+}$ and $\mathrm{Fe}^{3+}$ cannot move easily out of the channels due to their considerable large hydrated radii. Besides that heat of hydration of the cations have a considerable effect on the exchange process. Wood et al. [21] discussed the relationship between the heat of hydration of exchangeable cations in the clinoptiloite-rich mineral and exchange degree. They concluded that monovalent cations bond to their waters of hydration with much less energy than do divalent cations, and there is a direct relationship between the strength of the bond and hydration radius at a fixed valance state. Thus, cation exchange in zeolites actually occurs in association with water molecules-with more water molecules bonding more tightly to the smaller, highly charged cations [18, 22].

Another factor affecting the degree of exchange is the cation positions in clinoptilolite. The higher exchange seen for $\mathrm{Ca}^{2+}$ ion, indicated in Table 3 and Fig. $3 \mathrm{c}$, can be explained by its location within the structure. The cations $\mathrm{Na}^{+}$and $\mathrm{Ca}^{2+}$ are located in channel A, site M1and M2,

Table 3 The average weight \% of the major cations versus time for microwave and waterbath treated samples [23]

\begin{tabular}{|c|c|c|c|c|c|c|c|c|c|c|c|c|c|c|c|c|}
\hline \multirow[b]{3}{*}{$\mathrm{CaO}$} & \multirow{2}{*}{\multicolumn{2}{|c|}{ Original }} & \multicolumn{6}{|c|}{ Microwave treatment } & \multicolumn{8}{|c|}{ Waterbath treatment } \\
\hline & & & \multicolumn{2}{|c|}{$10 \mathrm{~min}$} & \multicolumn{2}{|c|}{$60 \mathrm{~min}$} & \multicolumn{2}{|c|}{$120 \mathrm{~min}$} & \multicolumn{2}{|c|}{$10 \mathrm{~min}$} & \multicolumn{2}{|c|}{$60 \mathrm{~min}$} & \multicolumn{2}{|c|}{$120 \mathrm{~min}$} & \multicolumn{2}{|c|}{2 weeks } \\
\hline & 2.03 & 2.54 & 2.23 & 1.42 & 1.53 & 1.55 & 1.48 & 1.47 & 2.18 & 2.17 & 2.25 & 2.25 & 1.07 & 1.07 & 0.62 & 0.61 \\
\hline $\mathrm{Fe}_{2} \mathrm{O}_{3}$ & 1.03 & 1.18 & 0.89 & 1.04 & 0.82 & 0.83 & 1.09 & 1.09 & 1.17 & 1.15 & 0.97 & 1.09 & 1.08 & 1.07 & 0.89 & 0.88 \\
\hline $\mathrm{K}_{2} \mathrm{O}$ & 2.23 & 2.24 & 2.03 & 1.67 & 1.62 & 1.65 & 2.42 & 2.44 & 2.06 & 2.03 & 2.26 & 1.97 & 1.91 & 1.90 & 1.95 & 1.94 \\
\hline $\mathrm{MgO}$ & 1.19 & 1.51 & 0.82 & 0.92 & 0.76 & 0.77 & 089 & 0.90 & 1.15 & 1.35 & 0.94 & 0.94 & 0.93 & 0.94 & 0.44 & 0.44 \\
\hline $\mathrm{Na}_{2} \mathrm{O}$ & 0.52 & 0.53 & 2.19 & 2.03 & 2.30 & 2.32 & 3.28 & 3.31 & 1.56 & 1.54 & 2.20 & 2.30 & 2.27 & 2.27 & 3.25 & 3.24 \\
\hline$\% \mathrm{CBE}^{\mathrm{a}}$ & 0.08 & & 8.19 & & 1.53 & & 14.54 & & 6.43 & & 13.05 & & 2.33 & & 13.61 & \\
\hline
\end{tabular}

${ }^{\mathrm{a}}$ Cation balance error $(\mathrm{CBE}) \%=\left[\left(\mathrm{Al}^{3+}+\mathrm{Fe}^{3+}\right)-\left(\mathrm{Na}^{+}+\mathrm{K}^{+}+2 \mathrm{Ca}^{2+}+2 \mathrm{Mg}^{2+}\right)\right] /\left[\mathrm{Al}^{3+}+\mathrm{Fe}^{3+}\right] \times 100$ 

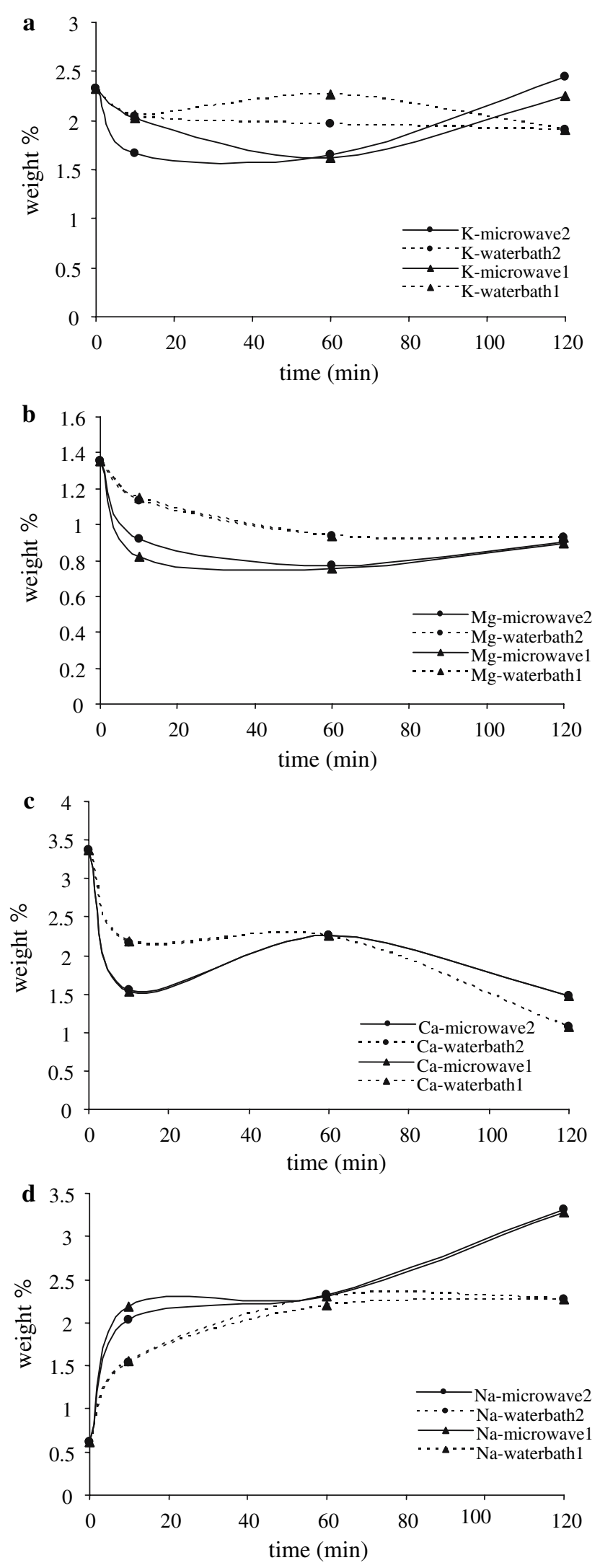

Fig. 3 The weight \% change of major cations versus time using microwave and waterbath treatment [23]
Table 4 The properties of exchangeable cations

\begin{tabular}{lllll}
\hline Cation & $\begin{array}{l}\text { Ionic radius } \\
(\AA)\end{array}$ & $\begin{array}{l}\text { Hydrated radiu- } \\
\mathrm{s}^{\mathrm{a}}(\AA)\end{array}$ & $\begin{array}{l}\text { Heats of } \\
(\mathrm{kcal} / \mathrm{mol})\end{array}$ & hydration $^{\mathrm{b}}$ \\
\hline $\mathrm{Na}^{+}$ & 0.95 & 3.58 & 97 & \\
$\mathrm{~K}^{+}$ & 1.33 & 3.31 & 79 & \\
$\mathrm{Mg}^{2+}$ & 0.65 & 4.28 & 450 & \\
$\mathrm{Ca}^{2+}$ & 0.99 & 4.12 & 373 & \\
$\mathrm{Fe}^{3+}$ & 0.75 & 4.28 & $1057^{\mathrm{c}}$ & \\
\hline
\end{tabular}

a Semmens et al. [17]

b Woods and Gunter [21]

${ }^{c}$ http://www.chem.ox.ac.uk/teaching/Exams2005/PartIBGenInorg.pdf

$\mathrm{K}^{+}$and $\mathrm{Ba}^{2+}$ are in channel $\mathrm{C}$, site $\mathrm{M} 3$, and $\mathrm{Mg}^{2+}$ is in channel A, site M4 in the clinoptilolite structure. The $\mathrm{Na}^{+}$ in the solution probably goes to site M1 in the clinoptilolite where $\mathrm{Ca}^{2+}$ ions are located. Since $\mathrm{Ca}^{2+}$ ions are located in channel A having the size of $4.4 \times 7.2 \AA$ the ion exchange is easier. Moreover, $\mathrm{Ca}^{2+}$ ions are coordinated with three framework oxygen atoms and five water molecules, which makes $\mathrm{Ca}^{2+}$ be easily removable from the clinoptilolite structure [6]. $\mathrm{K}^{+}$is coordinated with six framework oxygen atoms and three water molecules, the strong bonding of $\mathrm{K}^{+}$at this site may affect its lower exchangeability [7, 10]. As indicated in Table 3 and Fig. 3a, there was a slight change in the amount of $\mathrm{K}^{+}$ during the whole exchange periods for both cases. The slight increase in the 120 min microwave treatment case might be due to properties of the natural minerals even though it has been homogenized before use or due to experimental and/or instrumental error. $\mathrm{Ca}^{2+}$ and $\mathrm{Mg}^{2+}$ amounts were lower in the 2 week waterbath treatment case might be caused by the behavior of these cations in aqueous media or their locations within the clinopitlolite structure. Moreover, if the exchange was further continued in the microwave case possibly lower amounts of these cations could be obtained as it was observed in the waterbath case. Detail research is required in this respect.

The XRD patterns of the clinoptilolite in microwave and conventional waterbath treatment after 1 and $2 \mathrm{~h}$ are given in Fig. 4.

The characteristic peaks for clinoptilolite outlined by Arcoya et al. [7] at $9.92^{\circ}, 22.43^{\circ}$ and $30.50^{\circ} 2 \theta$ were also observed in this study and denoted by " $\mathrm{C}$ " on the $\mathrm{XRD}$ patterns of the samples as given Fig. 4. Those peaks were still observed after microwave and waterbath treated samples with slight intensity increase or decrease which might be caused by the difference in sample preparation. The non-zeolitic peak around $35^{\circ} 2 \theta$ in the XRD pattern of the original mineral disappeared after treatments. As a conclusion, microwave irradiation does not change the structure of the clinoptilolite rich sample. 
Fig. 4 XRD patterns of original and treated clinoptilolite minerals, Bigadiç

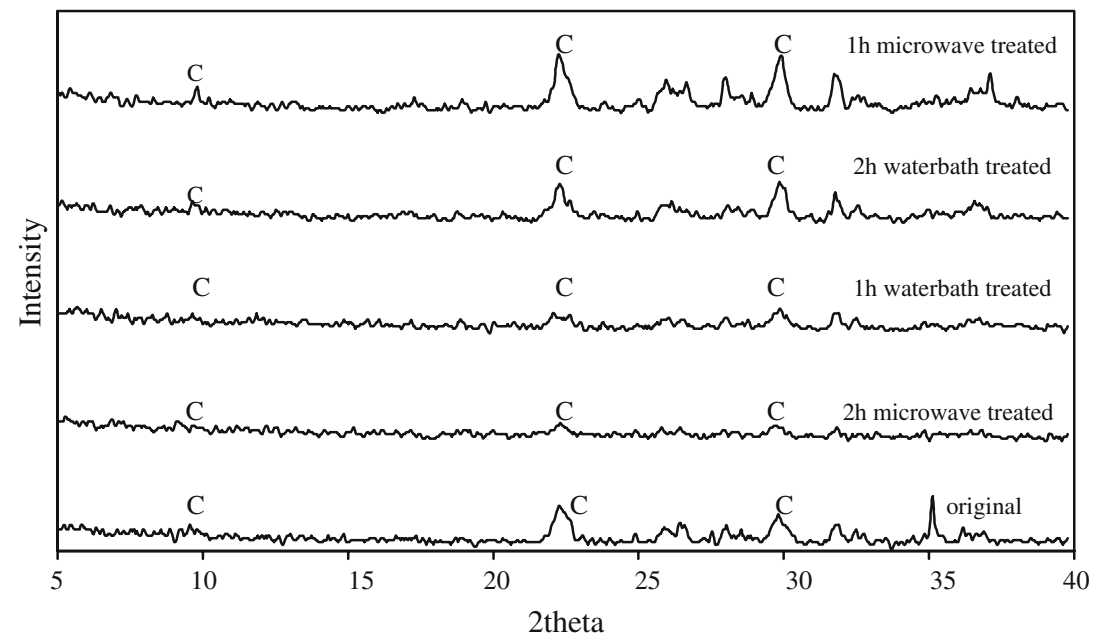

\section{Conclusions}

In this study, the kinetics and efficiency of the $\mathrm{Na}^{+}$ exchange process using Bigadiç clinoptilolite, under microwave irradiation in comparison with the conventional waterbath treatment versus time was examined.

$\mathrm{Na}^{2+}$ amount was found lower in waterbath case even the exchange in waterbath continued for two more weeks over the period of microwave treatment. $\mathrm{Na}^{+}$exchange rate was found to be highest for $\mathrm{Ca}^{2+}$ ion compared to $\mathrm{Mg}^{2+}$ and $\mathrm{K}^{+}$ions for both of the treatments. The XRD patterns of microwave exchanged minerals showed that under the given conditions microwave irradiation did not result in any structural changes of the mineral. Exchange results confirm that higher exchange degree can possibly be obtained by microwave treatment.

Consequently, the microwave treatment can be considered as an effective, rapid and reliable method compared to conventionally used waterbath treatments that can be used to prepare ion-exchanged minerals for different purposes.

Acknowledgments The authors gratefully acknowledge to $\mathrm{F}$ Dr. Fahri ESENLI, İstanbul Technical University, Mining Faculty, for estimation of the mineral content of the Bigadiç sample.

\section{References}

1. H. Van Bekkum, E.M. Flenigen, J.C. Jansen, in Introduction to Zeolite Science and Practice, ed. by H. Van Bekkum, E.M. Flaingen, J.C. Jansen (Elsevier Science Publishing Company Inc., New York NY USA, 1991)
2. T. Ohgushi, K. Ishimaru, Phys. Chem. Chem. Phys. 2, 2779 (2000)

3. Palaban, R.T., Geochim. Cosmochim. Acta 21, 4573 (1994)

4. G. Magdalena, K. Pavelic, Microporous Mesoporus Mater. 79, 165 (2005)

5. M. Rivera-Garza, M.T. Olguin, I. Garcia-Sosa, D. Alcantara, G. Rodriguez-Fuentes, Microporous Mesoporous Mater. 39, $444(2000)$

6. G.V. Tsitsishvilli, T.G. Andronikashhvilli, L.D. Filizova, G.N. Kırova, in Natural Zeolites (Ellis Horwood Limited, England, 1992)

7. A. Arcoya, J.A. Gonzales, G. Llabre, X.L. Seoane, N. Traviesco, Microporous Mater. 7, 1 (1996)

8. X. Xu, W. Yang, J. Liu, L. Lin, Sep. Purif. Technol. 25, 241 (2001)

9. E. Haque Kazi, Int. J. Mineral Process. 57, 1 (1999)

10. M.A. Jama, H. Yücel, Sep. Sci. Technol. 14, 1393 (1989)

11. U.D. Joshi, P.N. Joshi, S.S. Tamhankar, V.P. Joshi, B.B. Idage, V.V. Joshi, V.P. Shiralkar, Thermochem. Acta, 387, 121 (2002)

12. H. Katsuki, S. Furuta, S. Komarneni, J. Porous Mater. 8, 5 (2001)

13. J.L. Palmer, M.E. Gunter, Am. Mineral. 86, 431 (2001)

14. Z. Pilter, S. Szabo', M. Hasznos-Nezdei, E. Palai-Varsanyi, Microporous Mesoporous Mater. 40, 257 (2000)

15. M.D. Romero, G. Ovejero, M.A. Uguina, A. Rodriguez, J.M. Gomez, Catal. Commun. 5, 157 (2004)

16. S.A. Stout, S. Komarneni, Clay Clay Minerals 50, 248 (2002)

17. M.J. Semmens, M. Seyfath, Environ. Sci. Technol. 11, 517 (1975)

18. A. Top, S. Ülkü, Appl. Clay Sci. 27, 13 (2004)

19. B.J. Whittington, N.B. Milestone, Zeolites 12, 815 (1992)

20. Y. Han, H. Ma, S. Qui, F.-S. Xiao, Microporous Mesaporous Mater. 30, 283 (1998)

21. R.-M. Woods, M.E. Gunter, Am. Mineral. 86, 424 (2001)

22. E. Crazan, J. Papp, A. Meszaros-Kis, E. Domokos, Acta Chim. Hungar. 5, 673 (1989)

23. Y. Akdeniz, MSc Thesis, İzmir Institute of Technology, (1999) 